archives-ouvertes

\title{
Out-of-body experience in vestibular disorders - A prospective study of 210 patients with dizziness
}

Christophe Lopez

\section{To cite this version:}

Christophe Lopez. Out-of-body experience in vestibular disorders - A prospective study of 210 patients with dizziness. Cortex, Elsevier, 2018, 104, pp.193-206. 10.1016/j.cortex.2017.05.026 . hal-02121673

\section{HAL Id: hal-02121673 \\ https://hal-amu.archives-ouvertes.fr/hal-02121673}

Submitted on 6 May 2019

HAL is a multi-disciplinary open access archive for the deposit and dissemination of scientific research documents, whether they are published or not. The documents may come from teaching and research institutions in France or abroad, or from public or private research centers.
L'archive ouverte pluridisciplinaire HAL, est destinée au dépôt et à la diffusion de documents scientifiques de niveau recherche, publiés ou non, émanant des établissements d'enseignement et de recherche français ou étrangers, des laboratoires publics ou privés. 


\title{
Special issue: Research report \\ Out-of-body experience in vestibular disorders - A prospective study of $\mathbf{2 1 0}$ patients with dizziness
}

\author{
Christophe Lopez ${ }^{a, *}$ and Maya Elzière ${ }^{b}$ \\ a Aix Marseille Univ, CNRS, LNIA, FR3C, Marseille, France \\ ${ }^{\mathrm{b}}$ Centre des Vertiges, Hôpital Européen, Marseille, France
}

Keywords:

Vestibular system

Out-of-body experience

Sensory conflict

Bodily self-consciousness

Self-location

\begin{abstract}
A B S T R A C T
Out-of-body experiences (OBEs) are states during which people experience their centre of awareness as located outside of their physical body, along with the sensation of seeing the environment from an elevated viewpoint. OBE is encountered in epilepsy, migraine and depersonalization, and it is not an uncommon experience in the general population. Current neuroscientific models of bodily self-consciousness consider that OBE are related to a failure to integrate visual, somatosensory and vestibular signals. These models have highlighted the importance of visual-vestibular mismatch in OBE. Case reports from older clinical literature suggest that vestibular disorders may precipitate OBE, but we were lacking population-based evidence that OBE is related to vestibular disorders. The present observational, prospective study describes otoneurological, neuropsychological and phenomenological correlates of OBE in the largest sample of patients with dizziness to date $(n=210)$ compared to a group of age- and gender-matched controls with no history of dizziness $(n=210)$. We show a significantly higher occurrence of OBE in patients with dizziness $(14 \%)$ than in healthy participants $(5 \%)$. Most of the patients experienced OBE only after they started having dizziness for the first time. OBE in patients with dizziness were mainly related to peripheral vestibular disorders. We also identify depersonalization-derealization, depression and anxiety as the main predictors of OBE in patients with dizziness, as well as a contribution of migraine. Depersonalizationderealization was the only significant predictor of $\mathrm{OBE}$ in healthy controls. Altogether, our data indicate that $\mathrm{OBE}$ in patients with dizziness may arise from a combination of perceptual incoherence evoked by the vestibular dysfunction with psychological factors (depersonalization-derealization, depression and anxiety) and neurological factors (migraine).
\end{abstract}

\footnotetext{
* Corresponding author. Laboratoire de Neurosciences Intégratives et Adaptatives - UMR 7260, Aix Marseille Université, Centre National de la Recherche Scientifique (CNRS), Centre Saint-Charles, Fédération de Recherche 3C - Case B, 3, Place Victor Hugo, 13331 Marseille Cedex 03, France.

E-mail address: christophe.lopez@univ-amu.fr (C. Lopez). 


\section{Introduction}

Out-of-body experiences (OBEs) are states during which people experience their "self", "mind", or centre of awareness, as located outside of their physical body. During an OBE, people seem to be fully awake and often report a sensation of floating along with the impression of seeing the environment from an elevated position (Blackmore, 1982; Blanke \& Dieguez, 2009; Brugger, 1997). OBE is not an uncommon experience in the general population and it is also encountered in conditions such as epilepsy, migraine and depersonalization (Blanke \& Dieguez, 2009; Blanke \& Mohr, 2005). This has resulted in a surge of interest from neurologists and neuroscientists over the past two decades to understand OBEs and provide a better comprehension of the sensorimotor and neurophysiological foundations of self-consciousness (Blanke, 2012; Brugger, 1997; Ionta et al., 2011; Kessler \& Braithwaite, 2016; Metzinger, 2009).

Current neuroscientific models of bodily selfconsciousness propose that accurate integration of visual, tactile, proprioceptive, interoceptive, motor and vestibular signals supports the experience of an embodied self (Blanke, 2012). OBEs are thus seen as a failure to coherently integrate these signals. A large body of evidence from neurology and research in healthy participants support this proposition. First, OBEs have been evoked in patients during electrical stimulations of the temporo-parietal junction, where they very likely interfere with multisensory processing (Blanke, Ortigue, Landis, \& Seeck, 2002; Bos, Spoor, Smits, Schouten, \& Vincent, 2016). Second, OBEs due to epilepsy or stroke are often associated with complex multisensory illusions, such as visual sensations (including autoscopy: the sensation of looking at one's own body), somesthetic sensations (the perceived shape and size of the body is distorted), and vestibular sensations (Blanke \& Mohr, 2005; Blanke, Landis, Spinelli, \& Seeck, 2004; Devinsky, Feldmann, Burrowes, \& Bromfield, 1989; Lopez, Halje, \& Blanke, 2008; Lopez, Heydrich, Seeck, \& Blanke, 2010). Third, recent studies in neurologically normal participants show that the perceived location of the "self" is altered when conflicts are created between visual and tactile signals (Ehrsson, 2007; Ionta et al., 2011; Lenggenhager, Mouthon, \& Blanke, 2009; Lenggenhager, Tadi, Metzinger, \& Blanke, 2007). These paradigms can evoke the feeling that the participants' viewpoint is disembodied and that they self-identify with a distant avatar.

The vestibular contributions to the sense of self and embodiment have been poorly described when compared to the role of vision and touch, despite the crucial role of the vestibular system in the perception of self-motion and orientation (Blanke, 2012; Ferrè \& Haggard, 2016; Lenggenhager \& Lopez, 2015; Lopez et al., 2008). In a recent study, healthy participants who received low-intensity galvanic stimulation of the vestibular nerves were more likely to adopt an embodied perspective to perceive letters traced on their forehead (Ferrè, Lopez, \& Haggard, 2014). The authors proposed that low-intensity vestibular stimulation increases the natural tendency of the vestibular system to anchor the self to the body, suggesting a vestibular contribution to embodied self-location. Another way to examine the vestibular contribution to embodiment would be to investigate patients with vestibular disorders. If vestibular signals are central for anchoring the self to the body (Ferrè et al., 2014), patients suffering from vestibular disorders may be more prone to OBE.

An older clinical literature review only found some cases of patients with dizziness reporting abnormal sense of embodiment, and extremely rare cases of full-blown OBE in vestibular disorders (reviewed in Lopez, 2013). In the 19th Century, Krishaber (1873) was probably the first to report abnormal self and bodily perceptions in patients with dizziness, followed by Bonnier (1905), who described apparent dissociations between the self and the body. One of Bonnier's patients reported "he was divided into two persons, one who had not changed posture, and another new person on his right, looking somewhat outwardly. Then the two somatic individuals approached each other, merged, and the vertigo disappeared". Three decades later, Skworzoff (1931) established a link between vestibular disorders and illusory perceptions of doubles (autoscopic phenomena), as one of his patients suffering from dizziness reported seeing and feeling every day his own double. Schilder (1935) proposed that normal vestibular functions are required for a normal body schema and described several patients with dizziness who experienced abnormal perceptions of their body shape and size. Yet, these patients did not receive systematic otoneurological examinations. The sensations often reported by Krishaber (1873), Bonnier (1905) and Schilder (1935) that the self feels strange, unreal and disconnected from the body in patients with dizziness are reminiscent of symptoms of depersonalization. There is evidence that Menière's disease can evoke symptoms resembling depersonalization (e.g., "I feel like I'm outside of myself. I feel like I'm not in myself"; Grigsby \& Johnston, 1989) and that depersonalization is more frequent and severe in patients with dizziness (Jauregui-Renaud, Sang, Gresty, Green, \& Bronstein, 2008; Tschan, Wiltink, Adler, Beutel, \& Michal, 2013; Sang, Jauregui-Renaud, Green, Bronstein, \& Gresty, 2006; reviewed in Jauregui-Renaud, 2015). Depersonalization is also often associated with anxiety and depression during dizziness (Tschan et al., 2013). Because of the lack of detailed phenomenology of disembodiment and the absence of systematic OBE questionnaires in older case reports (Bonnier, 1905; Grigsby \& Johnston, 1989; Krishaber, 1873; Schilder, 1935; Skworzoff, 1931), the relation between vestibular disorders, $\mathrm{OBE}$ and depersonalization remains unclear. Finally, we note the recent description of one patient with a unilateral vestibular dysfunction who experienced OBEs (Kaliuzhna, Vibert, Grivaz, \& Blanke, 2015). When tested in visuo-tactile conflicts known to evoke disembodied selflocation (Lenggenhager et al., 2007), the patient reported a stronger feeling of elevated, disembodied self-location than control participants, suggesting a role of vestibular signals in OBE. In conclusion, despite anecdotal cases collected over more than a century, we lack convincing evidence of fullblown disembodiment related to vestibular disorders, as there has been to date no systematic neuropsychological and otoneurological investigations of OBE in a large population of patients with dizziness.

The present study describes otoneurological, neuropsychological and phenomenological correlates of OBE in the largest sample of patients with dizziness to date. We first 
aimed at measuring the occurrence and describing the phenomenology of OBE in patients with dizziness, as done for epilepsy (Devinsky et al., 1989), stroke (Ionta et al., 2011), migraine (Podoll \& Robinson, 1999), near-death experience (van Lommel, Wees, Meyers, \& Elfferich, 2001), and sleep paralysis (Cheyne \& Girard, 2009). Second, the study aimed at clarifying the relations between depersonalization and OBE in patients with dizziness and healthy participants.

\section{Methods}

\subsection{Participants}

This prospective, observational study was conducted in patients referred to our otoneurological centre for dizziness and vertigo, defined as having the feeling of spinning, swaying or tilting, that they were off balance, or that the room around them was spinning (Brandt, Dieterich, \& Strupp, 2013). We included 210 patients with dizziness (143 females and 67 males; mean age \pm SD: $51 \pm 15.6$ years) who matched the inclusion criteria (age over 18, ability to read and understand the questionnaires, no severe neurological or psychiatric disorders) and gave their consent to participate in the study. Depending on the patient's symptoms, otoneurological examination included audiological assessment, videonystagmographic examination of spontaneous nystagmus, positional nystagmus, head shaking test (HST), pendular rotatory test and caloric test, video head impulse test (VHIT), cervical vestibular-evoked myogenic potentials (cVEMPs), and MRI with contrast injection. Forms of dizziness and the most common aetiologies are summarized in Table 1. 111 (54\%) patients had peripheral vestibular disorders including benign paroxysmal positional vertigo (BPPV), Menière's disease, perilymphatic fistula and inner ear malformations, or other acute unilateral vestibular disorders, as the most common aetiology. 24 (11\%) patients had central forms of dizziness, 14 (6\%) had somatoform (psychogenic) dizziness, and 4 (2\%) had dizziness from other another origin. The exact origin of dizziness was unknown in 57 (27\%) patients, some of which presented with nystagmus and objective signs of vestibular dysfunction (Table 1). Otoneurological examinations showed that 147 patients presented with a spontaneous, positional or HST nystagmus at the time of the examination, and 81 patients had objective signs of vestibular dysfunctions, as evidenced by decreased gain of the horizontal vestibulo-ocular reflex during the VHIT (gain < .8), decreased caloric vestibular response (deficit $>25 \%$ ), and absent or asymmetrical cVEMPs. Patients were compared to 210 age-matched ( $48.4 \pm 14.7$ years) and gender-matched (146 females and 64 males) healthy control participants with no history of otoneurological and psychiatric disorders. Control participants were recruited at the same otoneurological centre, and included partners, family members and acquaintances that accompanied the patients $(n=109)$, as well as, hospital staff $(n=101)$. Table 2 summarizes the characteristics of the two populations in terms of age, gender, smoking and drinking habits, education level, marital status, employment status and history of migraine. Patients with dizziness and healthy controls were matched for age, gender, education level and smoking habits,

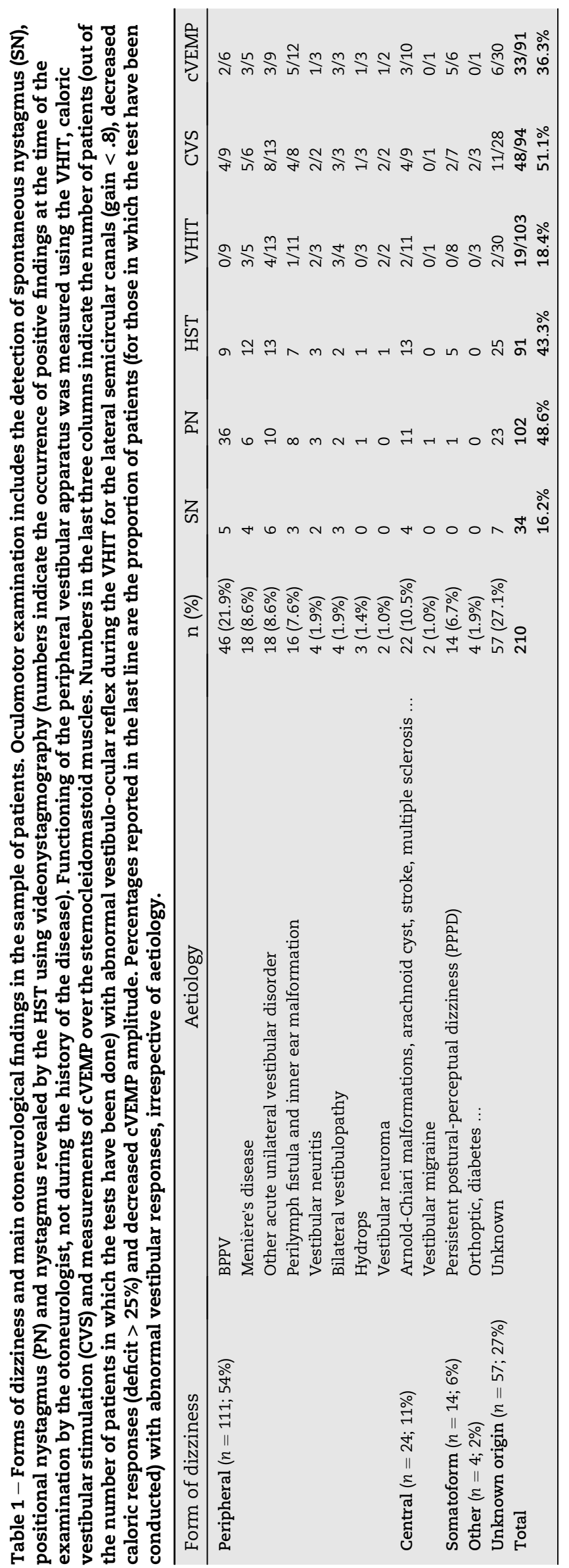


Table 2 - Demographic and clinical characteristics of patients with dizziness and healthy controls. Mean \pm SD is reported. Education level according to the French education system; Level 1: before high school; Level 2: accomplished high school; Level 3: two years after high school; Level 4: Bachelor's degree, Level 5: Master's degree, Engineering degree, PhD, MD.

\begin{tabular}{|c|c|c|c|c|c|c|c|}
\hline & \multicolumn{3}{|c|}{ Patients with dizziness } & \multicolumn{3}{|c|}{ Healthy controls } & \multirow{2}{*}{$\begin{array}{l}\text { Patients us. } \\
\text { controls }\end{array}$} \\
\hline & $\begin{array}{c}\text { All } \\
(n=210)\end{array}$ & $\begin{array}{l}\text { Without OBE } \\
(n=181)\end{array}$ & $\begin{array}{l}\text { With OBE } \\
(n=29)\end{array}$ & $\begin{array}{c}\text { All } \\
(n=210)\end{array}$ & $\begin{array}{l}\text { Without OBE } \\
(n=199)\end{array}$ & $\begin{array}{l}\text { With OBE } \\
(n=11)\end{array}$ & \\
\hline Age (years) & $51.0 \pm 15.6$ & $51.9 \pm 15.8$ & $44.9 \pm 12.8$ & $48.4 \pm 14.7$ & $48.8 \pm 14.8$ & $42.2 \pm 11.5$ & $\begin{array}{l}t=1.74 \\
P=.08\end{array}$ \\
\hline Females/Males & $143 / 67$ & $119 / 62$ & $24 / 5$ & $146 / 64$ & $137 / 62$ & $9 / 2$ & $\chi^{2}=.1$ \\
\hline Sex ratio & 2.13 & 1.92 & 4.8 & 2.28 & 2.21 & 4.5 & $P=.752$ \\
\hline \multicolumn{7}{|c|}{ Highest education level (\%): } & $\chi^{2}=8.18$ \\
\hline Level 1 & $34 \%$ & $34 \%$ & $32 \%$ & $23 \%$ & $24 \%$ & $9 \%$ & $P=.085$ \\
\hline Level 2 & $18 \%$ & $19 \%$ & $14.5 \%$ & $20 \%$ & $18.5 \%$ & $27.5 \%$ & \\
\hline Level 3 & $22 \%$ & $20.5 \%$ & $28.5 \%$ & $21 \%$ & $21.5 \%$ & $18 \%$ & \\
\hline Level 4 & $13 \%$ & $14 \%$ & $7 \%$ & $15 \%$ & $14 \%$ & $36.5 \%$ & \\
\hline Level 5 & $13 \%$ & $12.5 \%$ & $18 \%$ & $21 \%$ & $22 \%$ & $9 \%$ & \\
\hline \multicolumn{7}{|c|}{ Employment status (\%): } & $\chi^{2}=21.64$ \\
\hline Employed & $61 \%$ & $59.5 \%$ & $68 \%$ & $79 \%$ & $78.5 \%$ & $91 \%$ & $p<.001$ \\
\hline Student & $1.5 \%$ & $1 \%$ & $3.5 \%$ & $1.5 \%$ & $1.5 \%$ & $0 \%$ & \\
\hline Retired & $22 \%$ & $24 \%$ & $10.5 \%$ & $15.5 \%$ & $16.5 \%$ & $0 \%$ & \\
\hline Unemployed & $15.5 \%$ & $15.5 \%$ & $18 \%$ & $4 \%$ & $3.5 \%$ & $9 \%$ & \\
\hline \multicolumn{7}{|l|}{ Marital status (\%): } & $\chi^{2}=19.18$ \\
\hline Single & $21 \%$ & $19 \%$ & $32 \%$ & $14 \%$ & $13 \%$ & $36.5 \%$ & $p<.05$ \\
\hline Married/couple & $56.5 \%$ & $57 \%$ & $53.5 \%$ & $76.5 \%$ & $77 \%$ & $63.5 \%$ & \\
\hline Divorced/widowed & $22.5 \%$ & $24 \%$ & $14.5 \%$ & $9.5 \%$ & $10 \%$ & $0 \%$ & \\
\hline Smokers (\%) & $21.9 \%$ & $20.2 \%$ & $32.1 \%$ & $22.2 \%$ & $21.4 \%$ & $36.4 \%$ & $\begin{array}{l}\chi^{2}=.01 \\
P=.936\end{array}$ \\
\hline \multicolumn{7}{|c|}{ Alcohol consumption (\%): } & $\chi^{2}=13.77$ \\
\hline No alcohol & $63.5 \%$ & $62 \%$ & $72.5 \%$ & $48 \%$ & $48.5 \%$ & $36.5 \%$ & $p<.005$ \\
\hline 1 to 5 units/week & $31.5 \%$ & $33.5 \%$ & $20.5 \%$ & $39.5 \%$ & $39 \%$ & $54.5 \%$ & \\
\hline 6 to 10 units/week & $3.5 \%$ & $3.5 \%$ & $3.5 \%$ & $10.5 \%$ & $10.5 \%$ & $9 \%$ & \\
\hline$>10$ units/week & $1.5 \%$ & $1 \%$ & $3.5 \%$ & $2 \%$ & $2 \%$ & $0 \%$ & \\
\hline $\begin{array}{l}\text { History of dizziness } \\
\text { (months) }\end{array}$ & $68.5 \pm 103.2$ & $70.9 \pm 108.5$ & $49.3 \pm 59.5$ & - & - & - & - \\
\hline Migraine (\%) & $35.1 \%$ & $31.9 \%$ & $53.6 \%$ & $19.4 \%$ & $18.4 \%$ & $36.4 \%$ & $\begin{array}{l}\chi^{2}=12.16 \\
p<.0005\end{array}$ \\
\hline
\end{tabular}

whereas they differed with respect to employment status, marital status and alcohol consumption (i.e., alcohol consumption was lower in patients with dizziness than in controls). Our institutional Ethics Committee (Hôpital Européen, CEDP-HE16.03) approved all procedures for this observational study.

\subsection{Data recording}

The same otoneurologist recruited patients and controls, and procedures were explained to both groups similarly. Participants filled out an OBE questionnaire whose purpose was explicitly written: This questionnaire is about out-of-body sensations that you may have experienced while you were awake, that is outside the periods of sleep or dream, and outside any consumption of alcohol or drug. OBE was evaluated using Palmer's questionnaire (Palmer, 1979), later used by Terhune (2009): Have you ever had an experience in which you felt that "you" were "outside of" or "away from" your physical body; that is, the feeling that your consciousness, mind or centre of awareness was at a different place than your physical body? (If in doubt, please answer "no"). Participants ticked a "no" or "yes" box. Those who answered "yes" were invited to answer 5 more questions. Healthy controls answered these 5 questions once. Patients were asked whether they experienced OBE before they started having dizziness for the first time, and/or after they started having dizziness. Each patient answered these 5 questions for both periods:

(1) During the OBE, have you had visual experiences? Possible answers were: "no", "I am unsure", "yes", and "yes, and during this experience I saw my own body from the outside".

(2) During the OBE, have you had the feeling that the shape or size of your own body, or body parts, had changed? Possible answers were: "no", "I am unsure", and "yes" (participants could indicate which body part felt distorted).

(3) During the OBE, have you had the feeling that you moved (sensation of motion, lightness, elevation, etc.)? Possible answers were: "no", "I am unsure", and "yes" (participants could indicate the nature of the sensation).

(4) How long did the sensations of being out of the body last? Possible answers were: "a few seconds", "a few minutes", "a few hours", "about a day", "more than a day", and "more than a week".

(5) How many times did you have OBEs?

The introductory sentence ensured that we did not collect instances of OBEs that occurred during dreams or lucid dreams, neither during alcohol or drug consumption. The phrase "If in doubt, please answer 'no'" reduced the risk of false 
positives, but may have underestimated the occurrence of OBEs.

Participants also filled out the Hospital Anxiety and Depression scale (Zigmond \& Snaith, 1983), which includes seven items tapping into anxiety and seven items tapping into depression. Anxiety and depression scores each range from 0 to 21. Finally, patients filled out the Cambridge Depersonalization Scale (Sierra \& Berrios, 2000) which includes 29 items about depersonalization and derealization symptoms. Patients were asked whether they have had these 29 symptoms since they started experiencing dizziness for the first time (as in Sang et al., 2006), whereas control participants were asked whether they have had these experiences during the last 6 months (as in Sierra \& Berrios, 2000). The questionnaire was introduced as follows: This questionnaire describes strange and 'funny' experiences that normal people may have in their daily life. We are interested in their: (a) frequency, i.e., how often have you had these experiences [since you had dizziness for the first time (patients)/over the last 6 months (controls)]; and (b) their approximate duration (Sierra \& Berrios, 2000). For each item, participants indicated the frequency of the experience on a scale ranging from 0 ("never") to 4 ("all the time"), and the duration of the experience on a scale from 1 ("few seconds") to 6 ("more than a week"). The introductory paragraph indicated: If you are not sure, give your best guess. For each item, the global score (sum of the frequency and duration) ranged from 0 to 10 . The total score for the Cambridge Depersonalization Scale ranges from 0 to 290.

\subsection{Data analysis}

After stratification of patients and controls according to their answer to the Palmer's questionnaire (with vs without OBE), we compared their respective socio-economical and clinical data using two-tailed t-tests for independent samples for quantitative variables and $\chi^{2}$ tests for qualitative variables.

A multivariate analysis of covariance (MANCOVA) was calculated to clarify the relations between depersonalizationderealization, depression and anxiety in patients and healthy controls, with the occurrence of OBE (IBM SPSS Chicago, IL, USA). Depersonalization-derealization, depression and anxiety scores were the dependent variables, whereas group (patients, controls), OBE (with OBE, without OBE), gender, and migraine were fixed factors. Age, marital status, smoking habits, alcohol consumption, education and employment status were the covariates. When MANCOVA revealed an overall effect of a variable (i.e., significant Pillai's trace) on the dependent variables, univariate ANOVAs were conducted to determine which of the significant MANCOVA variables generated the significant multivariate effects.

In addition, we carried out receiver operating characteristics (ROC) curve analyses and binary logistic regression analyses (IBM SPSS Chicago, IL, USA) to determine how good the predictors (depersonalization-derealization score, anxiety score, depression score and each socio-economical and health variable) are to classify patients and controls as reporting OBE or not (for similar procedures in neuropsychology, see Gaser, Franke, Klöppel, Koutsouleris, Sauer, \& Alzheimer's Disease Neuroimaging Initiative, 2013; Moura et al., 2017; WhelanGoodinson, Ponsford, \& Schönberger, 2009). For the ROC curve analysis, we evaluated the area under the curve (AUC) as a measure of the accuracy of the classification. An AUC of .5 reflects results from a random classifier whereas an AUC of 1 reflects perfect sensitivity and specificity of the classifier. Discrimination is considered to have failed for an AUC between .5 and .6 , to be poor for an AUC between .6 and .7, fair for an AUC between .7 and .8, good for an AUC between .8 and .9, and excellent for an AUC between .9 and 1. Subsequently, we carried out binary logistic regression analyses, recommended for the analysis of independent variables that can take two possible values (i.e., with $\mathrm{OBE}$, without $\mathrm{OBE}$ ). Analyses used the Enter method, with OBE as the binary dependent variable, and with the following characteristics as covariates: depersonalization-derealization score, anxiety score, depression score, age, gender, migraine, marital status, smoking habits, alcohol consumption, education, employment status. Patients had additional covariates regarding the nature of their disease, including history of the disease, form of dizziness, and presence of a nystagmus. For all analyses, differences with a $p<.05$ were considered significant.

\section{Results}

\subsection{Occurrence of $\mathrm{OBE}$}

We observed that 29 out of 210 patients with dizziness (14\%), and 11 out of 210 healthy controls (5\%), reported having had an OBE. Importantly, patients were significantly more likely to report an OBE than healthy controls $\left(\chi^{2}=7.41, p<.01\right.$; Fig. $\left.1 \mathrm{~A}\right)$. The statistical power was $89 \%$ according to SAS V9.4 Power Procedure (SAS Institute Inc. Cary, NC). Another important finding was that the occurrence of OBE in patients was significantly modulated by the onset of dizziness $\left(\chi^{2}=9.92\right.$, $p<.01)$ : most patients with $\mathrm{OBE}(n=14,48 \%)$ had OBE only after they experienced dizziness for the first time. Seven patients with OBE (24\%) reported having had an OBE before and after they experienced dizziness, while $8(28 \%)$ had OBE only before they experienced dizziness (Fig. 1B).

\subsection{Phenomenology of $\mathrm{OBE}$}

Fig. 2 summarizes the phenomenological content of OBE. During their OBE, most of the patients experienced vestibular sensations (59\%; e.g., sensations of elevation and lightness, "sensation of being attracted by a spiral, like in a tunnel", "sensation of entering my body, like in an envelope, from the top"), while some experienced visual sensations (43\%). Only few patients reported a change in the perceived shape and size of their body, which affected their entire body, arms or head (15\%; e.g., "It feels as if my whole body was very small", "my cheek was bigger"), and autoscopy (8\%; e.g., "I saw myself, smaller, from the top"). Regarding the duration of the OBE, patients report it lasting for a few seconds $(42.5 \%)$ to a few minutes $(46 \%)$ or had these sensations several times for longer than a week (11.5\%). For patients who remembered the occurrence of OBEs, $87 \%$ reported multiple OBEs. The pattern of sensations was similar in healthy control participants (Fig. 2). The frequency of vestibular and visual sensations, as well as, body schema distortion and autoscopy in healthy controls did not differ from that reported in patients (all $\chi^{2}<1.07$ and $p>.3$ ). 
A

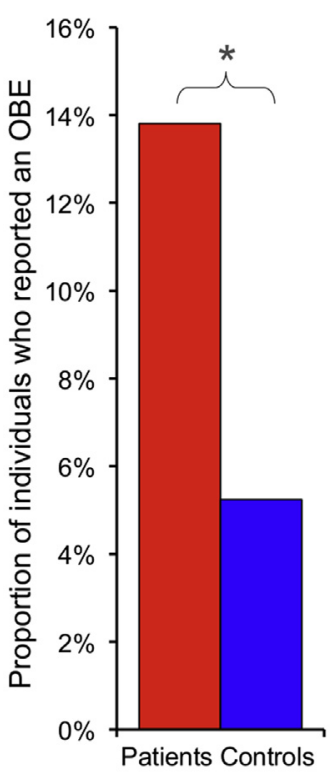

B

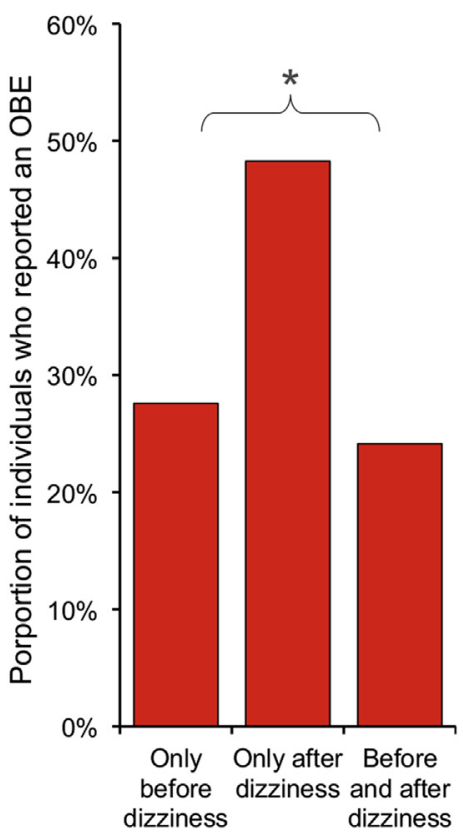

Fig. 1 - Occurrence of OBE. (A) Histogram shows higher occurrence of OBE in patients $(n=29)$ than control participants $(n=11)$. Asterisk indicates a significant difference between the two groups ( $\chi^{2}$ test). (B) Histogram shows the proportion of patients who reported OBE before, after, or before and after they experienced dizziness for the first time. Asterisk indicates that the distribution of $O B E$ depends significantly on the occurrence of dizziness $\left(\chi^{2}\right.$ goodness-of-fit test), with most patients reporting OBE only after they started experiencing dizziness.

\subsection{Characteristics of individuals reporting $O B E$}

Otoneurological findings in the 29 patients with OBE are summarized in Table 3 . We found that OBE was mainly due to

\section{PATIENTS}

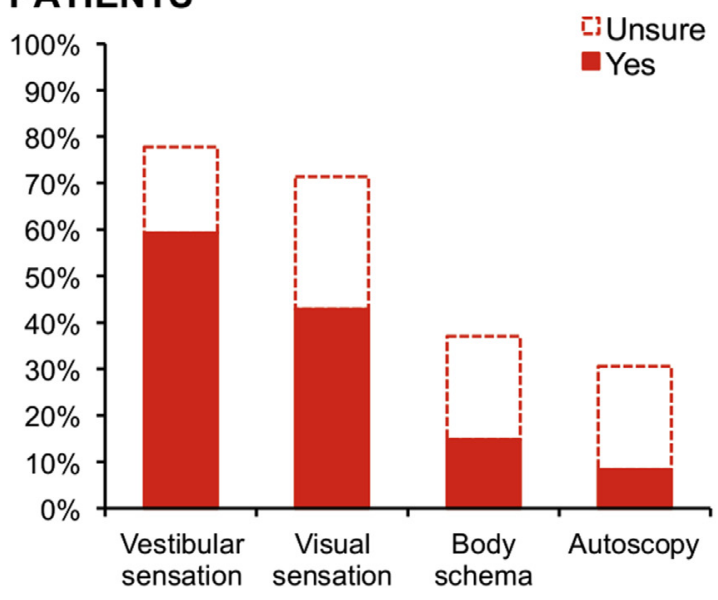

peripheral vestibular disorders $(n=23)$, including Menière's disease, vestibular neuritis, perilymphatic fistula and BPPV, with objective signs of an organic dysfunction. OBE associated to unilateral peripheral vestibular disorders was related to the left ear in eight patients and to the right ear in four patients (these proportions did not differ).

After stratification of the patients and controls according to their answer to the Palmer's questionnaire (Table 1), we found that patients with OBE differed from patients who never had $\mathrm{OBE}$ in that they were significantly younger (mean $\pm \mathrm{SD}$ : $44.9 \pm 12.8$ us $51.9 \pm 15.8$ years; $t=2.35, p<.05$ ) and more prone to migraine $\left(53.6 \%\right.$ us $\left.31.9 \% ; \chi^{2}=4.92, p<.05\right)$. There was a higher prevalence of OBEs in female $(n=24)$ than male $(n=5)$ patients, but the proportion did not differ from that in patients without OBE (statistical trend: $\chi^{2}=3.33, p=.068$ ). The prevalence of OBEs was not related to education level, employment status, marital status, smoking and drinking habits, or the history of the disease.

We compared vestibular responses in patients with and without OBE using the gain of the vestibulo-ocular reflex during the VHIT for the lateral semicircular canals (done in 14/29 patients with OBE and 79/181 patients without OBE) and the percentage of vestibular loss at the caloric test (done in $11 / 29$ patients with OBE and 67/181 patients without OBE). Patients with and without OBE had similar gain at the VHIT (right ear: $t=1.14, p=.26$; left ear: $t=.27, p=.79$ ) and similar vestibular loss at the caloric test $(t=.02, p=.98)$. Additional analyses showed that 20/29 (69\%) patients with OBE and 127/ 181 (70.2\%) patients without OBE presented with a spontaneous, positional, or a nystagmus at the HST (the proportions did not differ: $\chi^{2}=.017, p=.90$ ). Thus, clinical data available indicate similar vestibular function in patients with and without OBE.

In healthy controls, there was no difference between participants with $\mathrm{OBE}$ and participants without $\mathrm{OBE}$ regarding their age, gender, education level, employment status, marital status, smoking and drinking habits, or history of migraine.

\section{CONTROLS}

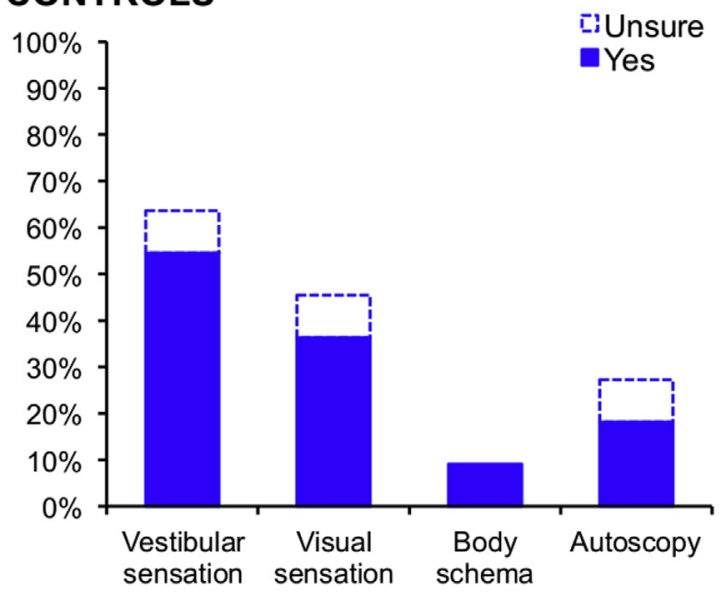

Fig. 2 - Phenomenology of OBE. The occurrence of the associated sensations did not differ significantly between patients with dizziness and healthy controls ( $\chi^{2}$ tests). "Body schema" refers to the perception of a distorted shape and size of the body. 
Table 3 - Demographic and clinical characteristics of patients reporting OBEs. BPPV: benign paroxysmal positional vertigo; PPPD: persistent postural-perceptual dizziness; SN: spontaneous nystagmus; PN: positional nystagmus; HST: nystagmus evoked by the head shaking test.

\begin{tabular}{|c|c|c|c|c|c|c|c|}
\hline & $\begin{array}{l}\text { Occurrence of OBE with respect } \\
\text { to the onset of the disease }\end{array}$ & Gender & Age (years) & Otoneurological findings and diagnosis & $\begin{array}{l}\text { History of the } \\
\text { disease (months) }\end{array}$ & $\begin{array}{l}\text { Nystagmus at the } \\
\text { time of examination }\end{array}$ & Migraine \\
\hline P1 & Only after & Female & 30 & PPPD, experience of room tilt illusions & 204 & No & Yes \\
\hline P2 & Only before & Female & 46 & Left vestibular neuritis, herpes infection & 9 & No & Yes \\
\hline P3 & Only after & Female & 32 & Right Menière's disease & $>180$ & HST & No \\
\hline P4 & Only after & Male & 42 & Left perilymphatic fistula & 72 & $\mathrm{PN}$ & No \\
\hline P5 & Only after & Female & 28 & $\begin{array}{l}\text { Chronic vestibulopathy of unknown origin, herpes } \\
\text { infection }\end{array}$ & 12 & No & Yes \\
\hline P6 & Only after & Male & 25 & PPPD & 4 & No & No \\
\hline P7 & Only after & Male & 44 & Cerebrospinal fluid hypotension & 4 & HST & - \\
\hline P8 & Only after & Female & 49 & Unknown & 53 & PN & Yes \\
\hline P9 & Only before & Female & 67 & Left acute unilateral vestibular disorder & 11 & $\mathrm{PN}$ & Yes \\
\hline P10 & Only after & Male & 33 & Vestibulopathy of unknown origin & 10 & No & No \\
\hline P11 & Only before & Female & 19 & Right vestibulopathy & .3 & SN & No \\
\hline P12 & Only before & Female & 55 & $\begin{array}{l}\text { Right lateral semicircular canal BPPV, arachnoid cyst, } \\
\text { experience of room tilt illusions }\end{array}$ & 24 & HST & No \\
\hline P13 & Before + after & Female & 36 & Chronic vestibulopathy of unknown origin & 8 & HST & Yes \\
\hline P14 & Only after & Male & 45 & History of BPPV, migraines with aura & 3 & No & Yes \\
\hline P15 & Only after & Female & 53 & Left Menière's disease & 36 & HST & Yes \\
\hline P16 & Before + after & Female & 64 & $\begin{array}{l}\text { Chronic vestibulopathy with positional vertigo, } \\
\text { herpes infection }\end{array}$ & 2 & PN & No \\
\hline P17 & Only after & Female & 65 & $\begin{array}{l}\text { Left acute unilateral vestibulopathy, left perilymphatic } \\
\text { fistula operated }\end{array}$ & 72 & SN, PN, HST & Yes \\
\hline P18 & Only before & Female & 51 & Right posterior canal BPPV & 1 & PN & No \\
\hline P19 & Only before & Female & 59 & Chronic vestibulopathy of unknown origin & 36 & No & No \\
\hline P20 & Only after & Female & 46 & Unknown & 20 & PN & No \\
\hline P21 & Before + after & Female & 43 & Destruction of the left lateral semicircular canal & 108 & No & Yes \\
\hline P22 & Only after & Female & 56 & Left semicircular canal dehiscence, positional vertigo & 96 & $\mathrm{SN}$ & Yes \\
\hline P23 & Only after & Female & 44 & PPPD & 27 & No & No \\
\hline P24 & Before + after & Female & 36 & Vestibulopathy of unknown origin & 4 & PN & Yes \\
\hline P25 & Only before & Female & 26 & Vestibulopathy of unknown origin, tinnitus & 180 & SN, HST & No \\
\hline P26 & Before + after & Female & 60 & Unilateral vestibulopathy of unknown origin & 144 & SN & Yes \\
\hline P27 & Before + after & Female & 57 & Vestibulopathy of unknown origin, tinnitus & 168 & PN & Yes \\
\hline P28 & Before + after & Female & 44 & Recurrent positional vertigo, tinnitus, herpes infection & 24 & PN & No \\
\hline P29 & Only before & Female & 46 & Left lateral semicircular canal BPPV & 48 & PN & Yes \\
\hline
\end{tabular}


3.4. Relation of OBE to depersonalization, depression and anxiety

Using Pillai's trace in the MANCOVA, we found a significant effect of OBE ( $\left.V=.77, F_{3,320}=8.937, p<.0001\right)$ and group $\left(\mathrm{V}=.46, F_{3,320}=5.087, p<.005\right)$ on depersonalizationderealization, depression and anxiety scores. No other significant main effects or interactions were observed. Thus, OBE and group were used as factors for separate univariate ANOVAs on the outcome variables (Fig. 3A).

A first univariate ANOVA on the depersonalizationderealization score revealed a significant main effect of group, with patients having significantly higher depersonalization-derealization scores than controls $\left(F_{1,416}=44.997, p<.00001\right)$. Importantly, there was a main effect of OBE, with significantly higher depersonalizationderealization scores in participants who reported OBE $\left(F_{1,416}=75.912, p<.00001\right)$. There was also a significant group $\times$ OBE interaction $\left(F_{1,416}=19.600, p<.0001\right)$, which is shown in Fig. 3A. Post-hoc analyses revealed that depersonalization-derealization scores were higher in patients with OBE than in patients without OBE $(88.6 \pm 65.3$ us $25.5 \pm 24.8$; planned comparison: $p<.0001)$. Similarly, depersonalization-derealization scores were higher in controls with OBE than without OBE $(35.1 \pm 29.6$ vs $14.4 \pm 15$; $t=4.17, p<.0001)$.

A second univariate ANOVA on the depression score showed a significant main effect of group, with patients having significantly higher depression scores than controls $\left(F_{1,412}=29.903, p<.00001\right)$. There was also a main effect of
A

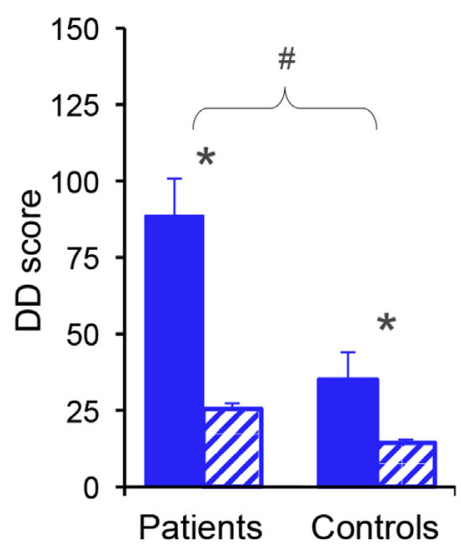

B

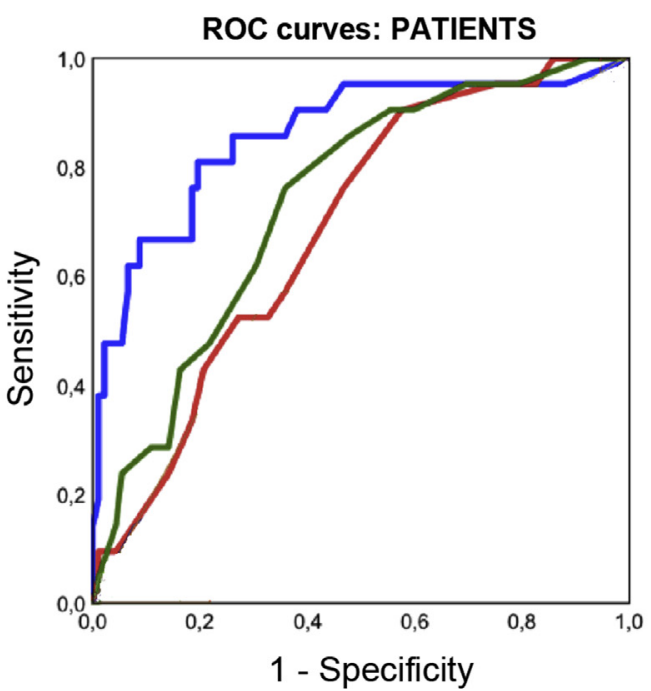

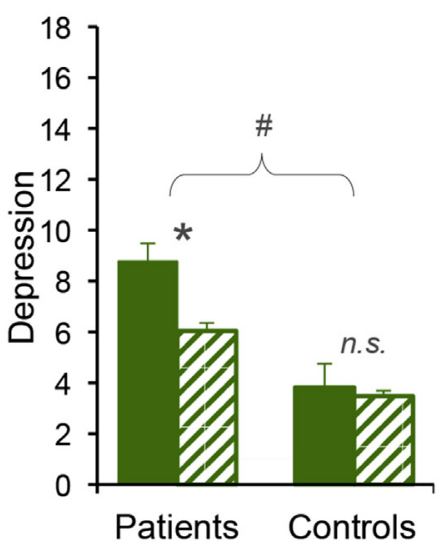

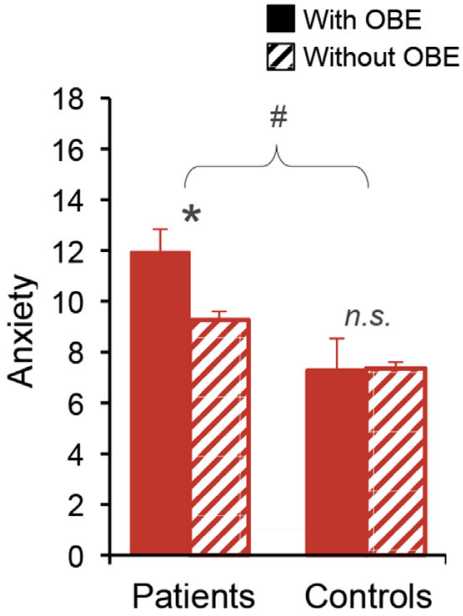

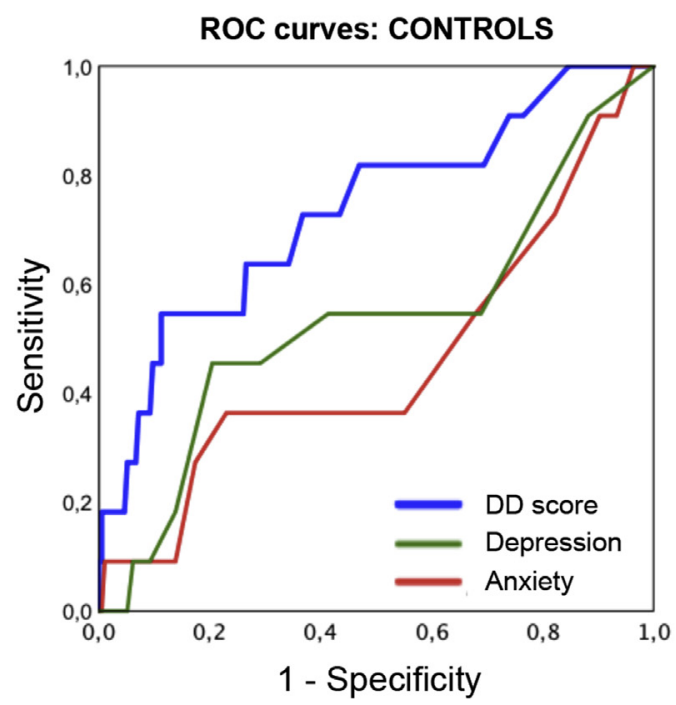

Fig. 3 - Relation between OBE and depersonalization-derealization, depression and anxiety. (A) Histograms illustrate the average depersonalization-derealization (DD) scores from the Cambridge Depersonalization Scale (Sierra \& Berrios, 2000) and the average depression and anxiety scores (mean \pm standard error of the mean) from the Hospital Anxiety and Depression scale (Zigmond \& Snaith, 1983). Asterisks indicate a significant difference between participants who experienced OBE (coloured bars) and participants who did not report OBE (hatched bars), and sharp signs indicate a significant difference between patients with dizziness and healthy controls (post-hoc planned comparisons). (B) ROC curves for detecting the occurrence of $O B E$ in patients with dizziness and healthy controls. 
OBE, whereby participants with OBE had significantly higher depression scores than participants without OBE $\left(F_{1,412}=4.898, p<.05\right)$. In addition, there was a statistical trend for the group $\times \mathrm{OBE}$ interaction $\left(F_{1,412}=2.922, p=.088\right)$. When exploring this statistical trend using post-hoc tests (Fig. 3A), we found that patients with OBE differed significantly from patients who never had OBE in that they had significantly higher depression scores $(8.8 \pm 3.8$ us $6.0 \pm 4.3 ; p<.005)$, whereas healthy controls with and without OBE had similar depression scores $(3.8 \pm 3.1$ us $3.5 \pm 3.0 ; p=.72)$.

Finally, a univariate ANOVA on the anxiety score showed a significant main effect of group, with significantly higher anxiety scores in patients with respect to controls $\left(F_{1,411}=19.454, p<.00005\right)$. In addition, we found a statistical trend for the main effect of OBE, with a trend for higher anxiety scores in participants with $\mathrm{OBE}$ than without $\mathrm{OBE}$ $\left(F_{1,411}=3.361, p=.067\right)$. There was also a statistical trend for the group $\times$ OBE interaction $\left(F_{1,411}=3.781, p=.053\right)$. Post-hoc analysis of this nearly significant interaction (Fig. 3A) showed that patients with OBE differed from patients who never had OBE in that they had significantly higher anxiety scores $(11.9 \pm 4.8$ us $9.3 \pm 4.6 ; p<.005)$. By contrast, healthy controls with and without OBE had similar anxiety scores $(7.3 \pm 4.2$ us $7.4 \pm 3.5 ; p=.94)$.

\subsection{Precipitating factors of $\mathrm{OBE}$}

Although the analyses reported above indicate that patients with and without OBE differ for some demographic and clinical data, we wanted to establish which variables successfully discriminate between participants with and without OBE, using ROC curve analysis and binary logistic regression.

The ROC curve analysis showed that three measures were relevant in discriminating between patients with and without OBE (Fig. 3B). Depersonalization-derealization score revealed excellent discrimination with AUC $=.859(p<.00001 ; 95 \%$ confidence interval (CI): .760-.959) and a standard error of .051. Depression was a fair predictor of OBE with AUC $=.737$ ( $p=.001 ; 95 \%$ CI: .628-.846) and a standard error of .056. Anxiety was a poor predictor of OBE with AUC = .688 ( $p=.007$; 95\% CI: .575-.801) and a standard error of .058. There was a poor contribution of the form of dizziness (peripheral, central, somatoform, unknown) with AUC $=.605$ ( $p=.135 ; 95 \%$ CI: $.465-.745)$ and a standard error of .071 , as well as, of the gender with AUC $=.602(p=.144 ; 95 \% \mathrm{CI}: .477-.728)$ and a standard error of .064 . There was no reliable discrimination based on age (AUC $=.406 ; p=.180$ ), migraine (AUC $=.588$; $p=.210$ ), marital status (AUC $=.405 ; p=.177$ ), smoking habits (AUC $=.550 ; p=.472$ ), alcohol consumption (AUC = .449; $p=.467$ ), education (AUC $=.501 ; p=.988$ ), employment status (AUC $=.466 ; p=.626$ ), history of the disease (AUC $=.490$; $p=.888$ ), and presence of a nystagmus (AUC $=.533 ; p=.637$ ).

In healthy controls (Fig. 3B), the ROC curve analysis showed that only the depersonalization-derealization score revealed fair classification with AUC $=.719$ ( $p=.015$; 95\% CI: .550-.888) and a standard error of .086. In contrast with patients, there was no reliable prediction from depression (AUC $=.541$; $p=.648$ ) and anxiety (AUC $=.466 ; p=.706$ ). These data however, should be taken with caution given the small number of healthy controls reporting OBE.
Binary logistic regression analysis in patients revealed that the depersonalization-derealization score was the only significant predictor of OBE $\left(\beta=-.060\right.$, Wald's $\chi^{2}=9.865, p<.005$, odds ratio: .942) while migraine was second, although not significant $\left(\beta=-1.461\right.$, Wald's $\chi^{2}=1.873, p=.171$, odds ratio: .232). This binary logistic regression model correctly classified $90.3 \%$ of patients regarding their report of an OBE, with $66.7 \%$ of true-positive, $95.6 \%$ of true-negative, $4.4 \%$ of false-positive and $33 \%$ of false-negative (Hosmer and Lemeshow goodnessof-fit test: $\chi^{2}(8)=8.943, p=.347$; Cow and Snell $R^{2}=.397$; Nagelkerke $R^{2}=.643$ ).

Binary logistic regression analysis in healthy controls also revealed that the depersonalization-derealization score was the only significant predictor of OBE $(\beta=-.063$, Wald's $\chi^{2}=6.111, p<.05$, odds ratio: .939). The second (although not significant) predictor was anxiety $\left(\beta=.202\right.$, Wald's $\chi^{2}=2.101$, $p=.147$, odds ratio: 1.224$)$. This binary logistic regression model correctly classified $94.5 \%$ of healthy controls. Yet, there was a low number of true-positive (18.2\%) and a high number of false-negative (81.8\%), with a low number of true-negative (99.4\%) and false-positive (.6\%) (Hosmer and Lemeshow goodness-of-fit test: $\chi^{2}(8)=10.668, p=.347$; Cow and Snell $R^{2}=.397$; Nagelkerke $R^{2}=.643$ ). Thus, classification in the controls does not seem as reliable as in patients and the small number of healthy participants reporting OBE imposes cautiousness with the interpretation of this result.

\section{Discussion}

This prospective study conducted in a large sample of participants shows that there is a significantly higher occurrence of OBE in patients with dizziness than in gender- and agematched healthy controls. We discuss the relation between vestibular disorders, disembodied experience, depersonalization-derealization, anxiety and depression in the framework of current multisensory models of selfconsciousness.

\subsection{Dizziness increases the occurrence of $\mathrm{OBE}$}

Our data provide support to intuitions from older literature that proposed relations between dizziness and disembodied experience (Bonnier, 1905; Krishaber, 1873; MenningerLerchenthal, 1935; Schilder, 1935; Skworzoff, 1931). While these studies did not quantify the occurrence of OBE in patients with dizziness, we showed that $14 \%$ of the patients have had at least one OBE, which is a significantly higher occurrence than in healthy controls (5\%).

Notably, OBE was not frequent in either group, indicating the reliability of the sensorimotor and cognitive mechanisms of embodiment. Earlier studies estimated that OBEs occur in about $10 \%$ of the general population (Blackmore, 1982; Blanke $\&$ Dieguez, 2009). The occurrence of OBE ranged from 8 to $50 \%$, depending on the tested population, but most studies were conducted in student populations (see Blackmore (1982) for a detailed review). For example, Palmer (1979) found OBE in 25\% of the students versus in $14 \%$ of the other inhabitants of Charlottesville, Virginia, whereas Green (1968) found OBE in $19 \%$ of the Southampton University students. Another survey 
found $\mathrm{OBE}$ in $8 \%$ of the Icelandic population (Haraldsson, Gudmundsdottir, Ragnarsson, Loftsson, \& Jonsson, 1977). The occurrence of OBE in our sample of healthy participants is lower than in previous studies. Importantly, our participants were selected on the basis that they had no history of dizziness, otoneurological or psychiatric disorders, which was not the case in previous investigations. Given that dizziness is a common condition affecting $11-30 \%$ of the population (Bigelow, Semenov, du Lac, Hoffman, \& Agrawal, 2016; Neuhauser, 2007), previous studies have inevitably measured OBE in participants with dizziness. Our study allows measuring the occurrence of OBE separately for participants with and without dizziness, showing that dizziness precipitates OBE.

\subsection{How vestibular disorders precipitate $\mathrm{OBE}$}

We observed that the majority of the patients experienced OBE only after they experienced dizziness for the first time. This indicates that dizziness is a triggering factor of $\mathrm{OBE}$. Multiple diseases of various aetiologies can evoke dizziness (Brandt et al., 2013). Here, we established that peripheral vestibular disorders were the most common cause of OBE in 29 patients, including vestibular neuritis, Meniere's disease, perilymphatic fistula and BPPV (Table 3). Importantly, we found objective signs of vestibular disorders in these patients (spontaneous, positional or HST nystagmus and decreased vestibulo-ocular reflex), indicating that OBE involves organic dysfunctions. Yet, vestibular functions did not differ between patients with and without $\mathrm{OBE}$, indicating that additional factors were involved, such as depersonalizationderealization, depression and anxiety (see below). In three patients, OBE was related to PPPD, which is close to phobic postural vertigo and chronic subjective dizziness (Dieterich \& Staab, 2017). While vestibular pathologies are associated with deficits in postural control and gaze stabilization, spatial navigation and cognition, we provide the first populationbased evidence that vestibular disorders can also evoke abnormal forms of embodiment.

The phenomenology of OBE indicates that most of the patients with dizziness and healthy participants experienced concomitant vestibular sensations. Our findings confirm and extend previously reported association between OBE and vestibular sensations (Brugger, 1997; Grüsser \& Landis, 1991; Menninger-Lerchenthal, 1935). This association is particularly evident from self-reports in neurological patients (Blanke et al., 2004; Devinsky et al., 1989; Heydrich, Lopez, Seeck, \& Blanke, 2011; Hécaen \& de Ajuriaguerra, 1952; Lopez et al., 2010), healthy participants (Blackmore, 1982; Green, 1968), and during sleep paralysis (Cheyne \& Girard, 2009). Other evidence comes from presurgical evaluation of epilepsy, showing that electrical stimulation of the temporo-parietal cortex evokes both vestibular sensations and OBE (Blanke et al., 2002; Penfield \& Jasper, 1954). Finally, experimental inductions of "OBE-like" experiences in healthy participants were characterized by self-location distant from the physical body, together with sensations of floating (Ionta et al., 2011; Lenggenhager et al., 2009). Altogether, this indicates that vestibular signals crucially contribute to the experience of embodiment.
What is the pathophysiology of OBE in vestibular disorders? According to Blanke and colleagues (Blanke \& Mohr, 2005; Blanke et al., 2004; Lopez et al., 2008), OBEs result from a multisensory disintegration in personal space (i.e., a failure to integrate visual body-related information and somatosensory information) and a disintegration between personal and extrapersonal space (i.e., a failure to integrate vestibular and visual information). This model emphasizes the conflict between vestibular and visual information and in this respect $O B E$ has been referred to as a "visuo-vestibular splitting of the somatosensory body image" (Grüsser \& Landis, 1991). Regarding the neuroanatomical bases of OBE, Grüsser and Landis (1991) proposed that OBE "is a combination of visual and vestibular hallucinations involving the posterior insula and retroinsular cortex", as the parieto-insular cortex is a visuo-vestibular-somatosensory area and the core of the vestibular cortex (Guldin \& Grüsser, 1998; Lopez, Blanke, \& Mast, 2012). The parieto-insular cortex is also the most frequently damaged area in neurological patients reporting OBE (Ionta et al., 2011). We propose that during acute vestibular disorders (e.g., Menière's disease, vestibular neuritis, BPPV), the central nervous system receives erroneous signals from the inner ear regarding body motion and orientation (e.g., sensation of body inclination to the right) that are conflicting with visual and somatosensory signals indicating another body position and motion (e.g., the body and the environment are upright). This sensory conflict would lead to perceptual incoherence and ultimately distort bodily self-consciousness (Lopez, 2013). The model holds true for patients with PPPD, also characterized by abnormal multisensory processing (Holle et al., 2015). For some patients with dizziness, perceptual incoherence may evoke full-blown $\mathrm{OBE}$, probably because of additional precipitating factors (i.e., depersonalization-derealization; see below), whereas for other patients perceptual incoherence may evoke simpler forms of depersonalization without full-blown OBE (Tschan et al., 2013).

\subsection{Relations between depersonalization-derealization and $\mathrm{OBE}$}

Multivariate and univariate analyses established relations between depersonalization-derealization scores and the occurrence of OBE in both patients and controls. We found that dizziness was associated with significantly higher depersonalization-derealization scores than in healthy controls, confirming previous investigations but in a larger sample (Jauregui-Renaud, 2015; Jauregui-Renaud et al., 2008; Kolev, Georgieva-Zhostova, \& Berthoz, 2014; Sang et al., 2006). In addition, depersonalization-derealization scores were significantly higher in both patients and controls with OBE compared to those without OBE. Importantly, ROC curve analysis and binary logistic regression identified depersonalization-derealization as the main predictor of $\mathrm{OBE}$ in patients and healthy controls.

Patients with OBE had particularly high depersonalizationderealization scores, whose average was above the cut-off value (70) for clinical depersonalization-derealization, but lower than the average score (119) of psychiatric patients diagnosed with depersonalization-derealization disorders 
(Sierra \& Berrios, 2000; Sierra, Baker, Medford, \& David, 2005). A previous investigation in patients with vestibular disorders showed higher scores of depersonalization-derealisation in anxious patients than in patients with low anxiety, establishing relations between mood disorders and self-perception (Kolev et al., 2014). As anxiety was also a significant predictor of OBE (see below), we suggest that anxiety and depersonalization-derealisation may combine to precipitate OBE in patients with dizziness.

Depersonalization-derealization was the only significant predictor of OBE in healthy controls. However, since only 11 controls reported an $\mathrm{OBE}$, this result should be taken with caution. In line with our finding, a study by Murray \& Fox (2005) showed that healthy participants with OBE report stronger somatoform dissociation, self-consciousness and body dissatisfaction when compared to participants without OBE. Another investigation in university students showed that individuals with $\mathrm{OBE}$ reported more perceptual anomalies associated with body-distortion processing (Braithwaite, Samson, Apperly, Broglia, \& Hulleman, 2011).

\subsection{Influence of anxiety and depression}

Overall patients with dizziness were more anxious and depressed than healthy controls. The reciprocal relations between dizziness and anxiety/depression are well established in the clinical literature: there is a high comorbidity of vestibular disorders with anxiety/depression, and anxious patients are more likely to experience vertigo (Bigelow et al., 2016; Eckhardt-Henn et al., 2008; Tschan et al., 2013; Yardley, Masson, Verschuur, Haacke, \& Luxon, 1992).

The ROC curve analysis indicated that depression was a predictor of OBE in patients with dizziness. Depression was also significantly higher in patients with OBE when compared to patients without OBE. Depression was similar in controls with and without OBE. We found no strong evidence in the literature to link OBE and depression. Bunning and Blanke (2005) reviewed cases of OBE in psychiatric patients and found that OBE was very rarely associated with depression. Depression has been related to autoscopic hallucination, but the origin of the viewpoint was not disembodied (Dening \& Berrios, 1994). A retrospective study in 550 patients with depression $(n=100)$, mania and schizophrenia, showed that depression was never associated with OBE (McGilchrist \& Cutting, 1995). This study found OBE only in acute schizophrenia. Our study provides the first evidence that depression, combined with other factors, precipitates OBE in patients with dizziness.

The ROC curve analysis also indicated that anxiety was a predictor of OBE in patients. We found that patients with OBE had significantly higher anxiety scores than patients without OBE, whereas anxiety scores were identical in healthy controls with and without OBE. This is consistent with previous comparisons of personality traits in healthy participants with and without OBE showing no difference with regards to their general anxiety (reviewed in Blanke \& Dieguez, 2009) or social anxiety (Murray \& Fox, 2005). The impact of anxiety on embodiment may differ in patients with dizziness, given their high level of anxiety. Mohr and Blanke (2005, p. 192) hypothesized that "anxiety is most closely linked to the form of [autoscopic phenomena] that is characterized by complete disembodiment (as in $\mathrm{OBE}$ ), also attributable to the vestibular involvement in anxiety and OBEs". Patients with high anxiety may be more prone to OBE, similarly to healthy individuals who experience OBE during stressful or life threatening situations (Blanke \& Dieguez, 2009; Brugger, Regard, Landis, \& Oelz, 1999).

\subsection{Other factors}

Migraine was more frequent in patients who reported OBE and was a predictor contributing only marginally to OBE. Migraine has been related to OBE in older clinical literature (Lippman, 1953; Podoll \& Robinson, 1999) and is often associated with dizziness (Lempert \& Neuhauser, 2009). When compared to patients with other vestibular disorders, patients with vestibular migraine have the highest risk of psychiatric comorbidities, including high anxiety and depression (Eckhardt-Henn et al., 2008; Lempert \& Neuhauser, 2009). Patients with migraine seem to be more sensitive to motion, as they have lower thresholds for vestibular perception (Lewis, Priesol, Nicoucar, Lim, \& Merfeld, 2011). More work is needed to understand how patients with migraine interpret selflocation and self-motion during situations of perceptual incoherence. We note that migraine is more frequent in females, which could explain why there tend to be more females in our sample of patients reporting OBE.

Finally, patients with OBE were younger than patients without OBE. This was not the case in healthy controls. Previous research has consistently found that there is no age or gender difference in the occurrence of OBE (Blackmore, 1982). Given that depersonalization-derealization scores were higher in patients with $\mathrm{OBE}$, and because depersonalization generally occurs in younger individuals (Simeon et al., 1997), this may explain partly why the group of patients with OBE was younger.

\subsection{Limitations of the study}

A limitation of the present study is that it relies on self-report assessment. Patients experienced difficulty reporting the phenomenology of their OBE, as they did not fill out the questionnaire immediately after an OBE. Patients reported complex experiences that may have occurred years ago, with inevitable imprecision of memories (see Blackmore (1982) for a detailed account). A strength of the study was that all patients with dizziness had a clinical diagnosis by an otoneurologist. Yet, we lack systematic recordings of all vestibular parameters in all patients, allowing detailed comparison of saccular, utricular and semicircular canals functions in patients with and without OBE. This is incompatible with otoneurological routine. For example, there is no systematic indication for $\mathrm{BPPV}$ to record vestibular-evoked myogenic potentials. In addition, we note several limitations regarding our sample of healthy controls. First, there was no otoneurological investigation in the healthy controls, which is practically undoable in this large sample. Second, only 11 healthy participants reported OBEs and therefore average demographic data, depersonalization-derealization, anxiety and depression scores calculated in this subpopulation should be taken with caution. Future studies should be conducted in larger samples 
of healthy participants to identify more precisely the predictors of their OBEs. Finally, a strength of our study was the large sample size $(n=420)$ and the inclusion of participants with a large range of age and socio-economical origins, different from the students populations usually tested in OBE studies.

\section{Conclusions}

Our study measured the occurrence of OBE in patients with dizziness and healthy participants. The vast majority of participants never experienced an OBE, indicating that the multisensory and neural underpinnings of embodied selflocation and visuo-spatial perspective are robust. Yet, we showed that dizziness increases the occurrence of OBE and identified peripheral vestibular disorders as a triggering factor of OBE. We also identified "OBE-prone" subpopulations in patients with dizziness and healthy controls, which cumulate several precipitating factors of otoneurological and psychological origin (Mohr \& Blanke, 2005). Patients who have had an OBE also exhibit comorbid depersonalization-derealization, anxiety and depression. Altogether, our data indicate that OBE in patients with dizziness may arise from a combination of perceptual incoherence (due to conflicting vestibular signals with other sensory signals about body orientation and motion) mainly with depersonalization-derealization, depression and anxiety, as well as migraine.

\section{Acknowledgements}

The research leading to these results has received funding from the People Programme (Marie Curie Actions) of the European Union's Seventh Framework Programme (FP7/ 2007-2013) under REA grant agreement number 333607 ("BODILYSELF, vestibular and multisensory investigations of bodily self-consciousness"). C. Lopez's research is supported by a grant from the VolkswagenStiftung (Grant no. 89434: "Finding Perspective: Determining the embodiment of perspectival experience"). The study has received support from the Hôpital Européen. We thank Dr A. Pavlidou and Dr. R. Ackerley for helpful comments on the manuscript and statistical analyses.

\section{R E F E R E N C E S}

Bigelow, R. T., Semenov, Y. R., du Lac, S., Hoffman, H. J., \& Agrawal, Y. (2016). Vestibular vertigo and comorbid cognitive and psychiatric impairment: The 2008 National Health Interview Survey. Journal of Neurology, Neurosurgery, and Psychiatry, 87(4), 367-372. http://dx.doi.org/10.1136/jnnp-2015310319.

Blackmore, S. J. (1982). Beyond the body: An investigation of out-ofthe-body experiences. London: Heinemann.

Blanke, O. (2012). Multisensory brain mechanisms of bodily selfconsciousness. Nature Reviews Neuroscience, 13(8), 556-571. http://dx.doi.org/10.1038/nrn3292.

Blanke, O., \& Dieguez, S. (2009). Leaving body and life behind: Outof-body and near-death experience. In S. Laureys, \& G. Tononi
(Eds.), The neurology of consciousness: Cognitive neuroscience and neuropathology (pp. 303-325). Amsterdam: Elsevier.

Blanke, O., Landis, T., Spinelli, L., \& Seeck, M. (2004). Out-of-body experience and autoscopy of neurological origin. Brain, 127, 243-258.

Blanke, O., \& Mohr, C. (2005). Out-of-body experience, heautoscopy, and autoscopic hallucination of neurological origin. Implications for neurocognitive mechanisms of corporeal awareness and self-consciousness. Brain Research Brain Research Reviews, 50, 184-199.

Blanke, O., Ortigue, S., Landis, T., \& Seeck, M. (2002). Stimulating illusory own-body perceptions. Nature, 419, 269-270.

Bonnier, P. (1905). L'Aschématie. Revue Neurologique (Paris), 12, 605-609.

Bos, E. M., Spoor, J. K. H., Smits, M., Schouten, J. W., \& Vincent, A. J. P. E. (2016). Out-of-body experience during awake craniotomy. World Neurosurgery, 92. http://dx.doi.org/10.1016/ j.wneu.2016.05.002, 586.e9-586.e13.

Braithwaite, J. J., Samson, D., Apperly, I., Broglia, E., \& Hulleman, J. (2011). Cognitive correlates of the spontaneous out-of-body experience (OBE) in the psychologically normal population: Evidence for an increased role of temporal-lobe instability, body-distortion processing, and impairments in own-body transformations. Cortex, 47(7), 839-853. http://dx.doi.org/ 10.1016/j.cortex.2010.05.002.

Brandt, T., Dieterich, M., \& Strupp, M. (2013). Vertigo and dizziness: Common complaints (2nd ed.). London: Springer London Ltd.

Brugger, P. (1997). Illusory reduplication of one's own body: Phenomenology and classification of autoscopic phenomena. Cognitive Neuropsychiatry, 2, 19-38.

Brugger, P., Regard, M., Landis, T., \& Oelz, O. (1999). Hallucinatory experiences in extreme-altitude climbers. Neuropsychiatry, Neuropsychology, and Behavioral Neurology, 12(1), 67-71.

Bunning, S., \& Blanke, O. (2005). The out-of body experience: Precipitating factors and neural correlates. Progress in Brain Research, 150, 331-350.

Cheyne, J. A., \& Girard, T. A. (2009). The body unbound: Vestibular-motor hallucinations and out-of-body experiences. Cortex, 45(2), 201-215. http://dx.doi.org/10.1016/ j.cortex.2007.05.002.

Dening, T. R., \& Berrios, G. E. (1994). Autoscopic phenomena. The British Journal of Psychiatry, 165(6), 808-817. http://dx.doi.org/ 10.1192/bjp.165.6.808.

Devinsky, O., Feldmann, E., Burrowes, K., \& Bromfield, E. (1989). Autoscopic phenomena with seizures. Archives of Neurology, 46, 1080-1088.

Dieterich, M., \& Staab, J. P. (2017). Functional dizziness: From phobic postural vertigo and chronic subjective dizziness to persistent postural-perceptual dizziness. Current Opinion in Neurology, 30(1), 107-113. http://dx.doi.org/10.1097/ WCO. 0000000000000417 .

Eckhardt-Henn, A., Best, C., Bense, S., Breuer, P., Diener, G., Tschan, R., et al. (2008). Psychiatric comorbidity in different organic vertigo syndromes. Journal of Neurology, 255, 420-428. http://dx.doi.org/10.1007/s00415-008-0697-x.

Ehrsson, H. H. (2007). The experimental induction of out-of-body experiences. Science, 317, 1048.

Ferrè, E. R., \& Haggard, P. (2016). The vestibular body: Vestibular contributions to bodily representations. Cognitive Neuropsychology, 33(1-2), 67-81. http://dx.doi.org/10.1080/ 02643294.2016 .1168390$.

Ferrè, E. R., Lopez, C., \& Haggard, P. (2014). Anchoring the self to the body: Vestibular contribution to the sense of self. Psychological Science, 25(11), 2106-2108. http://dx.doi.org/ 10.1177/0956797614547917.

Gaser, C., Franke, K., Klöppel, S., Koutsouleris, N., Sauer, H., \& Alzheimer's Disease Neuroimaging Initiative. (2013). BrainAGE in mild cognitive impaired patients: Predicting the conversion 
to Alzheimer's disease. PLoS One, 8(6), e67346. http:// dx.doi.org/10.1371/journal.pone.0067346.

Green, C. E. (1968). Out-of-body experiences. Oxford: Institute of Psychophysical Research.

Grigsby, J. P., \& Johnston, C. L. (1989). Depersonalization, vertigo and Meniere's disease. Psychological Reports, 64, 527-534.

Grüsser, O. J., \& Landis, T. (1991). The splitting of "I" and "me": Heautoscopy and related phenomena. In O. J. Grüsser, \& T. Landis (Eds.), Visual agnosias and other disturbances of visual perception and cognition (pp. 297-303). Amsterdam: MacMillan.

Guldin, W. O., \& Grüsser, O. J. (1998). Is there a vestibular cortex? Trends in Neurosciences, 21, 254-259.

Haraldsson, E., Gudmundsdottir, A., Ragnarsson, A., Loftsson, J., \& Jonsson, S. (1977). National survey of psychical experiences and attitudes towards the paranormal in Iceland. In J. D. Morris, W. G. Roll, \& R. L. Morris (Eds.), Research in parapsychology 1976 (pp. 182-186). Metuchen, N.J: Scarecrow Press.

Hécaen, H., \& de Ajuriaguerra, J. (1952). Méconnaissances et hallucinations corporelles. Intégration et désintégration de la somatognosie. Paris: Masson.

Heydrich, L., Lopez, C., Seeck, M., \& Blanke, O. (2011). Partial and full own-body illusions of epileptic origin in a child with right temporoparietal epilepsy. Epilepsy \& Behavior, 20, 583-586. http://dx.doi.org/10.1016/j.yebeh.2011.01.008. https://doi.org/ S1525-5050(11)00011-4.

Holle, D., Schulte-Steinberg, B., Wurthmann, S., Naegel, S., Ayzenberg, I., Diener, H.-C., et al. (2015). Persistent posturalperceptual dizziness: A matter of higher, central dysfunction? PLoS One, 10(11), e0142468. http://dx.doi.org/10.1371/ journal.pone.0142468.

Ionta, S., Heydrich, L., Lenggenhager, B., Mouthon, M., Fornari, E., Chapuis, D., et al. (2011). Multisensory mechanisms in temporo-parietal cortex support self-location and first-person perspective. Neuron, 70, 363-374. http://dx.doi.org/10.1016/ j.neuron.2011.03.009. https://doi.org/S0896-6273(11)00200-5.

Jauregui-Renaud, K. (2015). Vestibular function and depersonalization/derealization symptoms. Multisensory Research, 28(5-6), 637-651.

Jauregui-Renaud, K., Sang, F. Y., Gresty, M. A., Green, D. A., \& Bronstein, A. M. (2008). Depersonalisation/derealisation symptoms and updating orientation in patients with vestibular disease. Journal of Neurology, Neurosurgery \& Psychiatry, 79, 276-283. http://dx.doi.org/10.1136/ jnnp.2007.122119. https://doi.org/jnnp.2007.122119.

Kaliuzhna, M., Vibert, D., Grivaz, P., \& Blanke, O. (2015). Out-of-body experiences and other complex dissociation experiences in a patient with unilateral peripheral vestibular damage and deficient multisensory integration. Multisensory Research, 28(5-6), 613-635. http://dx.doi.org/10.1163/22134808-00002508.

Kessler, K., \& Braithwaite, J. J. (2016). Deliberate and spontaneous sensations of disembodiment: Capacity or flaw? Cognitive Neuropsychiatry, 21(5), 412-428. http://dx.doi.org/10.1080/ 13546805.2016.1203769.

Kolev, O. I., Georgieva-Zhostova, S. O., \& Berthoz, A. (2014). Anxiety changes depersonalization and derealization symptoms in vestibular patients. Behavioural Neurology, 2014, 847054. http://dx.doi.org/10.1155/2014/847054.

Krishaber, M. (1873). De la néuropathie cérébro-cardiaque. Paris: Masson.

Lempert, T., \& Neuhauser, H. (2009). Epidemiology of vertigo, migraine and vestibular migraine. Journal of Neurology, 256(3), 333-338. http://dx.doi.org/10.1007/s00415-009-0149-2.

Lenggenhager, B., \& Lopez, C. (2015). Vestibular contributions to the sense of body, self, and others. In T. Metzinger, \& J. M. Windt (Eds.), Open MIND (pp. 1-38). Frankfurt am Main: MIND-Group.
Lenggenhager, B., Mouthon, M., \& Blanke, O. (2009). Spatial aspects of bodily self-consciousness. Consciousness and Cognition, 18, 110-117.

Lenggenhager, B., Tadi, T., Metzinger, T., \& Blanke, O. (2007). Video ergo sum: Manipulating bodily self-consciousness. Science, 317, 1096-1099.

Lewis, R. F., Priesol, A. J., Nicoucar, K., Lim, K., \& Merfeld, D. M. (2011). Dynamic tilt thresholds are reduced in vestibular migraine. Journal of Vestibular Research, 21(6), 323-330. http:// dx.doi.org/10.3233/VES-2011-0422.

Lippman, C. W. (1953). Hallucinations of physical duality in migraine. The Journal of Nervous and Mental Disease, 117(4), 345-350.

van Lommel, P., Wees, R. van, Meyers, V., \& Elfferich, I. (2001). Near-death experience in survivors of cardiac arrest: A prospective study in The Netherlands. The Lancet, 358(9298), 2039-2045. http://dx.doi.org/10.1016/S01406736(01)07100-8.

Lopez, C. (2013). A neuroscientific account of how vestibular disorders impair bodily self-consciousness. Frontiers in Integrative Neuroscience, 7, 91. http://dx.doi.org/10.3389/ fnint.2013.00091.

Lopez, C., Blanke, O., \& Mast, F. W. (2012). The vestibular cortex in the human brain revealed by coordinate-based activation likelihood estimation meta-analysis. Neuroscience, 212, 159-179.

Lopez, C., Halje, P., \& Blanke, O. (2008). Body ownership and embodiment: Vestibular and multisensory mechanisms. Neurophysiologie Clinique, 38, 149-161.

Lopez, C., Heydrich, L., Seeck, M., \& Blanke, O. (2010). Abnormal self-location and vestibular vertigo in a patient with right frontal lobe epilepsy. Epilepsy \& Behavior, 17, 289-292. http:// dx.doi.org/10.1016/j.yebeh.2009.12.016. https://doi.org/S15255050(09)00694-5.

McGilchrist, I., \& Cutting, J. (1995). Somatic delusions in schizophrenia and the affective psychoses. The British Journal of Psychiatry: the Journal of Mental Science, 167(3), 350-361.

Menninger-Lerchenthal, E. (1935). Das Truggebilde der eigenen Gestalt. Berlin: Karger.

Metzinger, T. (2009). Why are out-of-body experiences interesting for philosophers? The theoretical relevance of OBE research. Cortex, 45(2), 256-258. http://dx.doi.org/10.1016/ j.cortex.2008.09.004.

Mohr, C., \& Blanke, O. (2005). The demystification of autoscopic phenomena: Experimental propositions. Current Psychiatry Reports, 7, 189-195.

Moura, O., Pereira, M., Alfaiate, C., Fernandes, E., Fernandes, B., Nogueira, S., et al. (2017). Neurocognitive functioning in children with developmental dyslexia and attention-deficit/ hyperactivity disorder: Multiple deficits and diagnostic accuracy. Journal of Clinical and Experimental Neuropsychology, 39(3), 296-312. http://dx.doi.org/10.1080/ 13803395.2016 .1225007$.

Murray, C. D., \& Fox, J. (2005a). Dissociational body experiences: Differences between respondents with and without prior outof-body-experiences. British Journal of Psychology, 96(Pt 4), 441-456. http://dx.doi.org/10.1348/000712605X49169.

Murray, C., \& Fox, J. (2005b). The out-of-body experience and body image: Differences between experiments and nonexperiments. The Journal of Nervous and Mental Disease, 193(1), 70-72.

Neuhauser, H. K. (2007). Epidemiology of vertigo. Current Opinion in Neurology, 20(1), 40-46. http://dx.doi.org/10.1097/ WCO.0b013e328013f432.

Palmer, J. (1979). A community mail survey of psychic experiences. Journal of the American Society for Psychical Research, 73(3), 221-251. 
Penfield, W., \& Jasper, H. (1954). Epilepsy and functional anatomy of the human brain. Boston: Little, Brown.

Podoll, K., \& Robinson, D. (1999). Out-of-body experiences and related phenomena in migraine art. Cephalalgia, 19, 886-896.

Sang, F. Y., Jauregui-Renaud, K., Green, D. A., Bronstein, A. M., \& Gresty, M. A. (2006). Depersonalisation/derealisation symptoms in vestibular disease. Journal of Neurology, Neurosurgery \& Psychiatry, 77, 760-766.

Schilder, P. (1935). The image and appearance of the human body. New York: International Universities Press.

Sierra, M., Baker, D., Medford, N., \& David, A. S. (2005). Unpacking the depersonalization syndrome: An exploratory factor analysis on the Cambridge Depersonalization Scale. Psychological Medicine, (10), 1523-1532. http://dx.doi.org/ 10.1017/S0033291705005325.

Sierra, M., \& Berrios, G. E. (2000). The Cambridge Depersonalization Scale: A new instrument for the measurement of depersonalization. Psychiatry Research, 93, 153-164.

Simeon, D., Gross, S., Guralnik, O., Stein, D. J., Schmeidler, J., \& Hollander, E. (1997). Feeling unreal: 30 cases of DSM-III-R depersonalization disorder. The American Journal of Psychiatry, 154, 1107-1113.

Skworzoff, K. (1931). Doppelgänger-Halluzinationen bei Kranken mit Funktionsstörungen des Labyrinths. Zeitschrift Für Die
Gesamte Neurologie Und Psychiatrie, 133(1), 762-766. http:// dx.doi.org/10.1007/BF02909953.

Terhune, D. B. (2009). The incidence and determinants of visual phenomenology during out-of-body experiences. Cortex, 45(2), 236-242. http://dx.doi.org/10.1016/j.cortex.2007.06.007.

Tschan, R., Wiltink, J., Adler, J., Beutel, M. E., \& Michal, M. (2013). Depersonalization experiences are strongly associated with dizziness and vertigo symptoms leading to increased health care consumption in the German general population. The Journal of Nervous and Mental Disease, 201(7), 629-635. http:// dx.doi.org/10.1097/NMD.0b013e3182982995.

Whelan-Goodinson, R., Ponsford, J., \& Schönberger, M. (2009). Validity of the Hospital Anxiety and Depression Scale to assess depression and anxiety following traumatic brain injury as compared with the structured clinical interview for DSM-IV. Journal of Affective Disorders, 114(1-3), 94-102. http:// dx.doi.org/10.1016/j.jad.2008.06.007.

Yardley, L., Masson, E., Verschuur, C., Haacke, N., \& Luxon, L. (1992). Symptoms, anxiety and handicap in dizzy patients: Development of the vertigo symptom scale. Journal of Psychosomatic Research, 36, 731-741.

Zigmond, A. S., \& Snaith, R. P. (1983). The hospital anxiety and depression scale. Acta Psychiatrica Scandinavica, 67(6), 361-370. http://dx.doi.org/10.1111/j.1600-0447.1983.tb09716.x. 